\author{
RELATIVE REFLECTIVITY OF VARIOUS BLACK PAINTS \\ C. Kerns, D. Owen, ${ }^{*}$ and A. Raymond \\ Reported by S. Pordes \\ March 1983
}

* Michigan State University 


\section{Relative Reflectivity of Various Black Paints}

C. Kerns, D. Owen, A. Raymond

This note gives the results of some measurements made to determine the relative reflectivity of various black paints. The measurements were made in the course of constructing a Cerenkov counter for the neutrino beam line. The counter operates by measuring the Cerenkov light emitted within a given angular aperture and a low reflectivity inner surface was necessary to reduce as much as possible the background from stray light. A second criterion was that the paint be hard to scratch or chip. (A previous counter had problems with paint chips migrating to the mirror surfaces.) The paint also had to be stable under vacuum since the pressure of the counter was cycled between absolute pressures of 10 microns and 1 atmosphere.

A sketch of the apparatus used is shown in figure 1. A sylvania RII30B Glow Modulator with a blue filter whose transmission peaked at 4300 Angstroms was used as the light source; the intensity of the reflected light was measured by an RCA 6342-A two inch photomultiplier tube. The light source was collimated to $+/-5$ degrees. Both the source and detector were pointed at the center of the sample and placed $12 \mathrm{~cm}$ from it.

The paints tested were :

A. Nextel Velvet Coating 101-Cl0 black (aerosol can): 3M Company, St. Paul, Minnesota, 55101 - available only from Edmund Scientific.

B. Nextel Suede Coating 3101-Cl0 black ( 3 component epoxy): 3M Company, St Paul, Minnesota, 55101

C. Krylon Ultra Flat Black 1602 (aerosol can): Borden Inc., Columbus, Ohio 43215

D. Kodak Paint \#20 (2 component epoxy) : Eastman Kodak Co., Kodak Aparatus Div., Rochester, NY, 14650 made available to us courtesy of Milton Gross, Special Products Division

E. Chemglaze 2306 Polyurethane Coating, flat black: Hughson Chemicals, Lord Corp. Erie, PA, 16512

F. Titanine Low Luster Black R66-6506: Vorac Corp., Carlstadt, NJ, 07072

Primers used were :
a. Zinc Chromate Primer Coating TT-P1757 (aeresol can): Aervoe-Pacific Co., P.O. Box 2112, San Leandro, CA., 94577
b. Nextel Primer 911-P4 light gray: 3M Company, St. Paul, Minnesota, 55101
c. Chemglaze Washprimer 9924 (2 component): Hughson Chemicals, Lord Corp., Erie, PA, 16512

The samples were prepared on $20 \times 30 \mathrm{~cm}$ sheets of aluminum which were degreased before primer was applied. The list of samples is given below. 


$\begin{array}{lccl}\text { Sample } & \text { Primer } & \text { Paint } & \text { Application } \\ \text { I } & a, b & \text { A } & \text { One coat sprayed on } \\ \text { II } & a, b & \text { B } & \text { One coat brushed on } \\ \text { III } & a, b & \text { B } & \text { Two coats sprayed on } \\ \text { IV } & a, b & \text { B } & \begin{array}{l}\text { Eight light coats } \\ \text { sprayed on }\end{array} \\ \text { V } & \text { a,b } & \text { C } & \begin{array}{l}\text { Two normal coats followed } \\ \text { by one light coat. }\end{array} \\ \text { VI } & \text { none } & \text { D } & \text { One coat sprayed on } \\ \text { VII } & \text { C } & \text { E } & \text { One coat brushed on } \\ \text { VIII } & \text { C } & \text { F } & \text { One coat brushed on }\end{array}$

\section{COMMENTS}

III. Surface more textured than II.

IV. The density of each coat was such that it required 6 to 8 coats to completely cover the primer. The final surface texture was similar to III but somewhat deeper.

VI. The surface had a sight glaze which probably would have been reduced with the application of several light coats.

VII. The surface was somewhat glazed. Application with a spray gun would probably result in a somewhat lower reflectivity.

VIII. Due to the fast drying characteristic of this paint it proved difficult to obtain a uniform coating. A spray gun would produce better results.

Results

Sample I (Nextel Velvet) was judged not to be hard enough since scratching it with a fingernail removed some of the paint. All other samples were considered to be of adequate hardness.

The results of the reflectivity measurements appear in Table 1. The values are normalized to those of sample I (3M Nextel Velvet) whose absolute reflectivity is about $2 \%$. Sample IV (Nextel Suede, 8 coats) had the lowest reflectivity, (typically a factor of 2 lower than the Nextel Velvet), and hence this paint was selected for most interior surfaces of the counter. A disadvantage of the Nextel suede is that it produces a relatively thick layer of paint. For this reason, in regions of the counter where the reflectivity is not 
critical we have chosen to paint moving parts (such as mirror mounts) with the Krylon paint (sample $V$ ). It may be mentioned that the Martin Marietta Corporation in Denver, Colorado has a proprietary electro-chemical treatment for aluminum which they claim produces the lowest reflectance surfaces available (which are stable under vacuum). Their reflectivity is about a factor of two lower than we were able to achieve. 
Table of Relative Reflectivities

\begin{tabular}{|c|c|c|c|c|c|c|c|}
\hline Samp & le $\backslash \begin{array}{l}\text { Angle In * } \\
\text { Angle out }\end{array}$ & $\begin{array}{l}70 \\
70\end{array}$ & $\begin{array}{l}45 \\
30\end{array}$ & $\begin{array}{l}45 \\
70\end{array}$ & $\begin{array}{l}45 \\
90\end{array}$ & $\begin{array}{l}90 \\
30\end{array}$ & $\begin{array}{l}90 \\
55\end{array}$ \\
\hline & $\begin{array}{l}\text { Nextel velvet } \\
\text { (sprayed } 2 \text { coats) }\end{array}$ & $\begin{array}{l}1.00 \\
(14.5)\end{array}$ & $\begin{array}{l}1.00 \\
(21.7)\end{array}$ & $\begin{array}{l}1.00 \\
(16.7)\end{array}$ & $\begin{array}{l}1.00 \\
(15.6)\end{array}$ & $\begin{array}{l}1.00 \\
(10.0)\end{array}$ & $\begin{array}{l}1.00 \\
(11.4)\end{array}$ \\
\hline II & $\begin{array}{c}\text { Nextel Suede } \\
\text { (brushed on) }\end{array}$ & 1.03 & 1.05 & 1.04 & 1.04 & 1.03 & 1.05 \\
\hline I I I & $\begin{array}{l}\text { Nextel suede } \\
\text { (sprayed } 2 \text { coats) }\end{array}$ & .69 & .78 & .60 & .74 & .64 & .77 \\
\hline IV & $\begin{array}{l}\text { Nextel Suede } \\
\text { (sprayed } 8 \text { coats) }\end{array}$ & .55 & .48 & .48 & .62 & .59 & .61 \\
\hline $\mathrm{V}$ & $\begin{array}{l}\text { Krylon } \\
\text { (sprayed } 2 \text { coats) }\end{array}$ & 1.54 & 1.75 & 1.56 & 1.25 & 1.20 & 1.34 \\
\hline VI & $\begin{array}{l}\text { Kodak no. } 20 \\
\text { (sprayed } 1 \text { coat) }\end{array}$ & 9.7 & 7.4 & 4.4 & 1.03 & .50 & 2.6 \\
\hline VII & $\begin{array}{l}\text { Chemglaze } \\
\text { (brushed on) }\end{array}$ & 4.6 & & & & & \\
\hline V I I I & $\begin{array}{l}\text { Titanine } \\
\text { (brushed on) }\end{array}$ & 2.7 & & & & & \\
\hline
\end{tabular}

* Angle are in degrees and are relative to the sample surface.

The figures in parenthesis show the actual amount of light detected at each setting of the apparatus. Note that most of the paints show no large specular reflection - the Kodak paint is an exception. 


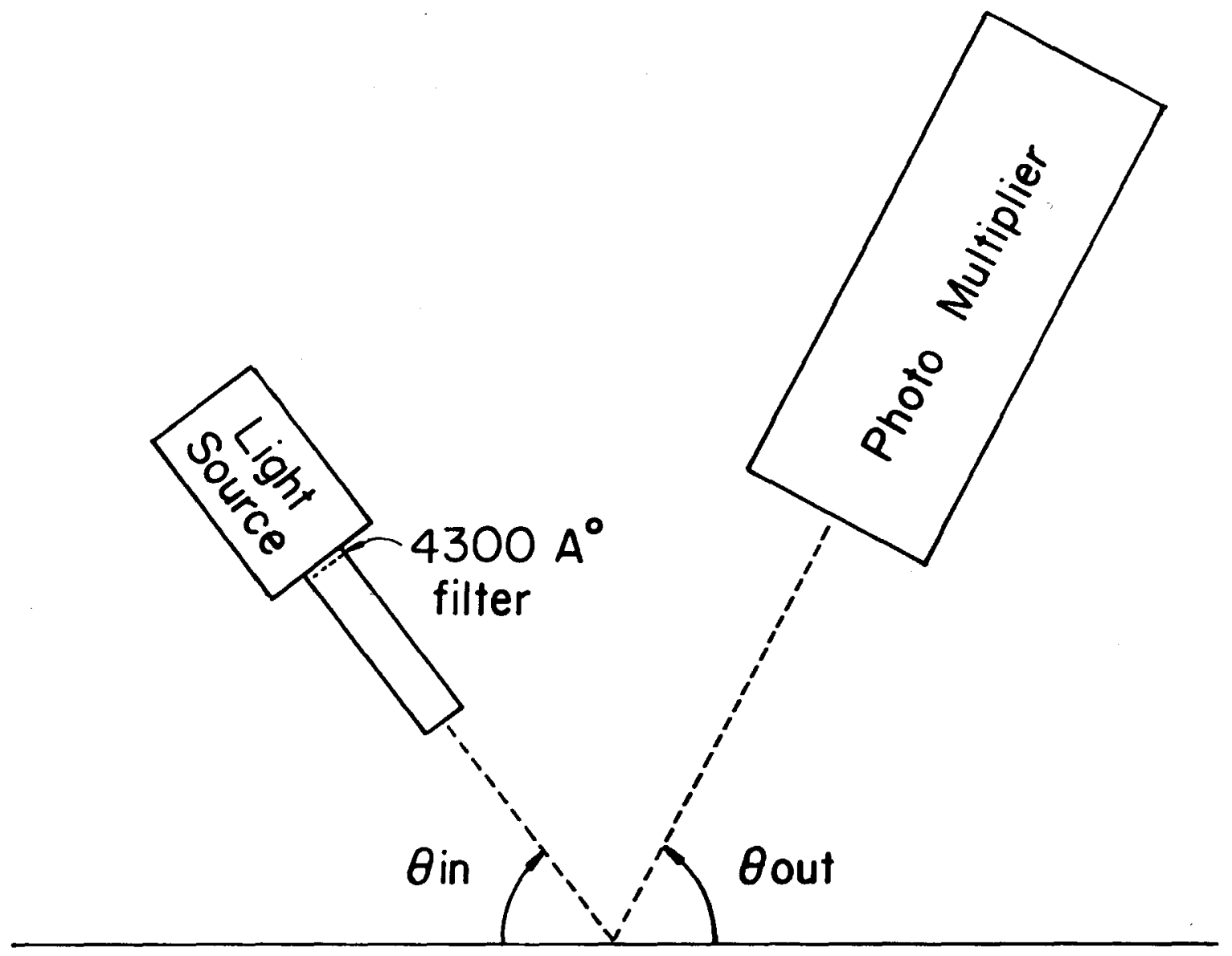

Sketch of Apparatus 